\title{
Study on the Key Influencing Factors of Consuming Will of Public Tea by the Public
}

\author{
Ping Chen \\ College of Economic \\ Fujian Agriculture and Forestry University \\ Fuzhou 350002
}

\author{
Jiangfan Yang \\ College of Horticulture \\ Fujian Agriculture and Forestry University \\ Fuzhou 350002
}

\begin{abstract}
In order to help the decision-making departments, enterprises and other related institutions find the key points of the policy implications to expand and sell public tea , this article is based on the survey data of 1419 social public, and uses the logistic regression analysis method to identify the key influencing factors of consuming will of public tea by the public. The main conclusions are as follows: The three variables of age, health motivation and tea awareness have a significant positive impact on consuming will of public tea. And the three variables of the number of children, the number of people around who drink the tea and the free taste in stores were significantly negative. The research on the influencing factors of consuming will of public tea is still a field of little concern in the academic field. The conclusion of this article has certain theoretical innovation significance and decisionmaking reference value.
\end{abstract}

Keywords-consuming will; influencing factors; public tea; logistic regression analysis

\section{INTRODUCTION}

Public tea is the tea whose price is suitable for public to purchase and drink themselves, also known as cheap tea, private tea. Learning the experience of scholars in the past, the price of public tea is at 101-500 yuan / $0.5 \mathrm{~kg}$ range [1]. Since the allround implementation of the "eight provisions of the central government", the "three public" consumption is limited, highquality tea, gift tea, business and policy tea and other non-public tea sales and profitability turned to be a significant decline. At the same time, the consumption of mid-class public tea in China is thriving, and the evolution of the process of the modernization, fashion, popularization and consumerization of tea consumption contains huge business opportunities. The sale of some tea industries and tea sale bodies which aim at ordinary consumers increases against odds. Various types of deep processing of tea products gradually germinate. And the fashion tea house, which is more convenient for the public to drink tea and makes people love tea life, develops rapidly. Chinese tea consumption market is led to "The Amalgamation of Ice and Fire" phenomenon. To sum up, with the deepening of China's political and economic reformation, gift tea, business and policy tea and other nonpublic tea products sales growth opportunities are gone, and public tea sales become the key point of business income and profitability. In this context, this article will collect the first-hand data through the questionnaire to understand the public's willingness to consume the public tea and identify the key influencing factors of the public's willingness to consume the public tea in order to provide the decision-making departments, enterprises and other industries with a basis for decision-making to promote and sell the public tea, pushing forward the process of "Tea for the National Drink". It will change the adverse situation that only a small number of people are addicted to the tea, making sure the survival and development of China's 80 million tea farmers, 70,000 tea and thousands of tea retail, which has important strategic significance.

\section{DATA SOURCES}

There are two kinds of questionnaire survey: field survey and network survey, both are taken randomly selected sample selection. The official questionnaire survey began in August 2016, field survey sites for Fuzhou City, Xiamen City, Quanzhou City, Zhangzhou City and some other cities in Fujian Province, 9 cities altogether, which lasted for a month; and network survey lasted for 3 months, aiming at the national general public. The main purpose is to expand the scope of the survey area under the limited funds to ensure the representation and typicality of the survey samples and to ensure the representativeness of the follow-up empirical research conclusions. Finally, a total of 1618 questionnaires were distributed, 908 copies and 710 copies were collected by network survey and field survey respectively. After the questionnaire data integrity check, there were 1419 copies effective questionnaires. Among them, the respondents include different age, different income, different gender, different qualifications and different occupations and other consumer groups.

\section{Model BuILding AND VARIABle SETting}

Referring to the research done by Liu Jiajia [2], Zhan Huibin [3], Zhang Mei[4] and other scholars, the article sets up a twodimensional variable--whether there is a public tea consumption willingness (yes $=1$, no $=0$ ), to measure the consumer willingness of the sample of the survey. The dependent variable (the willingness of public tea consumption) is a two-dimensional variable, not a continuous variable which does not conform to normal distribution, and it cannot be estimated by ordinary least square method or weighted least square method; at the same time, some potential effects of public tea consumption factor is a disorderly choice of the problem, there is no orderly arrangement. In view of this, this article chooses the binary Logit regression model to effectively identify the key influencing 
factors of the consumption of the public tea of the samples. Defines:

$$
p_{i}(y)=p_{i}^{y_{i}}(1-p)^{\left(1-y_{i}\right) i}, i=1,2, \ldots, n
$$

Among them, $=0$ or $=1(\mathrm{i}=1,2, \mathrm{n})$. Whether is 0 or 1 , is entirely determined by a particular observation, when $=1$; When $=0, \mathrm{Pi}$ is the probability of the occurrence of the consumption of the public tea; 1 - $\mathrm{Pi}$ is the probability of the absence of the consumption of the public tea. Take the natural logarithm on both sides of formula (1), and then get a linear function, that is, Logit model:

$$
\operatorname{Logit} P=\ln \left[\frac{p_{i}}{1-p_{i}}\right]=\alpha+\beta_{1} x_{1}+\beta_{2} x_{2}+\cdots+\beta_{m} x_{m}
$$

Among them, $\mathrm{x}$ is the potential influencing factor of the consumption intention of the public tea of the sample, which includes individual characteristics, consumption motive factors, cognitive factors and external environmental factors. Among them, learning from the research of Sandalidou et [5], Huang Zuhui et [6], personal characteristics include age, gender, education, occupation, marital status, the number of children and the number of people around who drink tea; consumption motives mainly investigates the reason why the sample consumes public tea. The cognitive factors mainly include three variables: tea cognition level, subjective index and quality identification; external environmental factors include the choice of tea packaging and public tea consumption channels. Specific potential factors and the explanations of them are shown in Table 1.

\begin{tabular}{|c|c|c|}
\hline Name of the variable & Symbol & Explanation of the Variable \\
\hline \multicolumn{3}{|l|}{$\begin{array}{c}\text { 1Personal } \\
\text { Characteristic }\end{array}$} \\
\hline Age & Age & $1=<18 ; 2=18-25 ; 3=26-35 ; 4=36-45 ; 5=46-60 ; 6=>60$ \\
\hline Gender & Gender & $1=$ male $; 2=$ female \\
\hline Education & Edu & $\begin{array}{l}1=\text { junior high school or below; } 2=\text { high school or secondary school } ; 3= \\
\text { college } ; 4=\text { undergraduate } ; 5=\text { master or above }\end{array}$ \\
\hline Employment & Employ & $\begin{array}{l}1=\text { civil servants } ; 2=\text { institutional staff; } 3=\text { enterprise and corporate } \\
\text { management } ; 4=\text { enterprise and company general staff } ; 5=\text { farmer; } 6= \\
\text { students } ; 7=\text { others }\end{array}$ \\
\hline Marital Status & Marital & $1=$ unmarried (divorced, widowed);2 = married \\
\hline $\begin{array}{l}\text { Number of the } \\
\text { Children }\end{array}$ & Children & $\begin{array}{l}1=\text { no child } ; 2=1 \text { child } ; 3=2 \text { children } ; 4=3 \text { children } ; 5=4 \text { children or } \\
\text { more }\end{array}$ \\
\hline $\begin{array}{c}\text { The Number of } \\
\text { People around Who } \\
\text { Drink Tea }\end{array}$ & Surround & $\begin{array}{l}1=\text { nearly all don't like; } 2 \text { = few people like; } 3=\text { some people like; } 4= \\
\text { many people like }\end{array}$ \\
\hline $\begin{array}{l}2 \text { Consumption } \\
\text { Motive Factor }\end{array}$ & Motiv & $1=$ refreshing and quench their thirst; $2=$ health care \\
\hline \multicolumn{3}{|l|}{$\begin{array}{l}3 \text { Cognitive } \\
\text { Factors }\end{array}$} \\
\hline $\begin{array}{l}\text { Tea Cognition } \\
\text { Level }\end{array}$ & Know & 1= don't know;2=know some;3=know well \\
\hline Subjective Index & Subject & $1=$ price $; 2=$ quality $; 3=$ brand \\
\hline $\begin{array}{c}\text { Quality } \\
\text { Identification }\end{array}$ & Identi & $1=$ price $; 2=$ taste I store; $3=$ the recommendation of others; $4=$ brand; $5=$ other \\
\hline $\begin{array}{c}4 \text { External } \\
\text { Environmental } \\
\text { Factors } \\
\text { Choice of Tea } \\
\text { Packaging } \\
\end{array}$ & Packing & $\begin{array}{l}1=\text { small separate package, iron (paper) box in bulk;2=with packing } \\
\text { box;3=don't care }\end{array}$ \\
\hline $\begin{array}{l}\text { Public Tea } \\
\text { Consumption } \\
\text { Channels }\end{array}$ & Channel & $\begin{array}{l}1=\text { tea wholesale market; } 2=\text { tea chain store; } 3=\text { gift from others; } 4 \\
=\text { counter in supermarket or store; } 5=\text { small tea shop; } 6=\text { consume via } \\
\text { Internet }\end{array}$ \\
\hline
\end{tabular}

TABLE I. THE POTENTIAL INFLUENCING FACTORS OF CONSUMING Will OF PUBlic TEA AND THE ExPLANATION 


\section{THE IDENTIFIABLE RESULTS OF THE KEY INFLUENCING FACTORS OF CONSUMING WILL OF PUBLIC TEA}

\section{A. The Survey Results of Overall Samples of Consuming Will of Public Tea}

Among the 1419 survey samples, there were 1128 samples of public tea consumption, accounting for $79.50 \%$, whilst only 291 respondents $(20.50 \%)$ expressed reluctance to buy public tea. The survey results above show that the survey sample is willing to purchase the public tea, which is good signal for tea processing industry, tea sales, etc., and it confirmed "public" trend of tea consumption once again.

\section{B. Identification and Discussion of the Key Influencing Factors}

Table 2 shows the results of the binary logit regression model, as follows:

(1)The regression coefficients of the three variables: age, health care motivation and tea cognition level, were significantly positive. Among them, when the "age" of survey sample levels up, the consumption of public tea will increase 2.109 times, indicating that with age growing, consumers tend to buy more affordable public tea. The reasons may be: the potential of young people's consumption of public tea need to be excavated, may be more likely to accept the "fast food" tea, such as blending delicious tea drinks, convenient and low-cost teabag; health care motivation compared to the basic function of "refreshing thirst", the consumers of public tea place more emphasis on health care function of tea, indicating that consumers are more and more cautious about their health, and tea with antioxidant, lowering blood pressure, lowering blood pressure, lowering blood sugar, softening blood vessels and other functions significantly affect the consumer's willingness to drink tea; the higher level of tea awareness, the higher the survey results of the public tea consumption will be, indicating that when consumers have a more comprehensive knowledge of tea, with enough experience and knowledge of tea identification, and are able to resonate with affordable, cost-effective large public tea , and then express a significant purchase will of public tea.

(2)The number of children, the number of people around who drink tea, and the taste in store, these three variables of the regression coefficient was significantly negative. Among them, the increase in the number of children will have a negative effect on the consumption of public tea, and the reason may be: the larger the number of children is, the more the family expenses will be, and the higher possibility of purchasing low-priced tea will be. With one child added, the willingness to consume will be reduced to the previous level of 0.167 times; every rise of a step of the number of people around who drink tea, the consumption of public tea of survey sample will be reduced by 0.443 times, indicating that with the increase in the number of people around who drink tea, it will be produce negative effects on consumption. It may be due to the fact that when more and more people are cultivating good habits of drinking tea, they will drive and influence more people to drink tea, and they may choose high-priced and high-quality tea to share and start social activities; "taste in store" as a dummy variable, compared with "price", the results show that consumers is more inclined to judge by "price" when it comes to the identification of tea quality, which may be mainly because consumers are limited to their tea knowledge level, and can not accurately determine the quality of tea through the "taste in store".

TABLE II. MODEL FitTing RESUlts

\begin{tabular}{|c|c|c|c|c|c|c|}
\hline Variable & $\begin{array}{c}\text { Regression } \\
\text { Coefficients }\end{array}$ & $\begin{array}{c}\text { Standard } \\
\text { Deviation }\end{array}$ & Wald Statistics & $\begin{array}{c}\text { Degrees } \\
\text { of } \\
\text { Freedom }\end{array}$ & $\begin{array}{c}\text { P } \\
\text { Value }\end{array}$ & Exp (B) \\
\hline Age & 0.746 & 0.348 & 4.609 & 1 & 0.032 & 2.109 \\
\hline Gender & -0.856 & 0.546 & 2.459 & 1 & 0.117 & 0.425 \\
\hline Edu & 0.158 & 0.311 & 0.258 & 1 & 0.612 & 1.171 \\
\hline Employ2 & -0.16 & 0.165 & 0.941 & 1 & 0.332 & 0.852 \\
\hline Employ3 & 0.225 & 0.456 & 0.245 & 1 & 0.621 & 1.253 \\
\hline Employ4 & 0.434 & 0.503 & 0.746 & 1 & 0.388 & 1.544 \\
\hline Employ5 & 0.046 & 0.446 & 0.011 & 1 & 0.918 & 1.047 \\
\hline Employ6 & -0.24 & 0.482 & 0.247 & 1 & 0.619 & 0.787 \\
\hline Marital & 0.75 & 0.844 & 0.789 & 1 & 0.375 & 2.116 \\
\hline Children & -1.793 & 0.679 & 6.967 & 1 & 0.008 & 0.167 \\
\hline Surround & -0.815 & 0.298 & 7.471 & 1 & 0.006 & 0.443 \\
\hline Motiv2 & 0.689 & 0.343 & 4.032 & 1 & 0.045 & 1.992 \\
\hline Know & 0.069 & 0.396 & 0.03 & 1 & 0.062 & 1.071 \\
\hline Subject2 & 0.276 & 0.846 & 0.572 & 1 & 0.458 & 1.292 \\
\hline Subject3 & 0.166 & 0.466 & 0.126 & 1 & 0.722 & 1.18 \\
\hline Identi2 & 0.256 & 0.345 & 0.552 & 1 & 0.048 & 1.292 \\
\hline Identi3 & -0.344 & 0.381 & 0.816 & 1 & 0.366 & 0.709 \\
\hline Identi4 & -0.003 & 0.316 & 0 & 1 & 0.992 & 0.997 \\
\hline
\end{tabular}




\begin{tabular}{|c|c|c|c|c|c|c|}
\hline \multicolumn{7}{|c|}{ Table II, cont. } \\
\hline Identi5 & 0.079 & 0.396 & 0.032 & 1 & 0.882 & 1.091 \\
\hline Packing2 & -0.336 & 0.565 & 0.252 & 1 & 0.058 & 1.722 \\
\hline Packing3 & 0.520 & 0.496 & 1.099 & 1 & 0.294 & 1.683 \\
\hline Packing4 & -0.093 & 0.074 & 1.601 & 1 & 0.206 & 0.911 \\
\hline Channel2 & 0.069 & 0.396 & 0.030 & 1 & 0.826 & 1.070 \\
\hline Channle3 & 0.527 & 0.694 & 0.577 & 1 & 0.448 & 1.694 \\
\hline Channel4 & -0.073 & 0.392 & 0.035 & 1 & 0.853 & 0.930 \\
\hline Channel5 & 0.462 & 0.284 & 2.654 & 1 & 0.103 & 1.587 \\
\hline Channel6 & 0.011 & 0.282 & 0.001 & 1 & 0.970 & 1.011 \\
\hline
\end{tabular}

\section{RESEARCH CONCLUSIONS AND POLICY IMPLICATIONS}

Based on the survey data of 1419 social subjects, this article uses the logistic regression analysis method to identify the key influencing factors of the public's willingness to consume the public tea. The main conclusions include: age, health motive and tea cognition level. The three variables have a significant positive impact, whilst the number of children, the number of people around who drink tea and the taste in store, these three variables has a significantly negative impact. The policy implications from the research conclusions above are mainly: the enterprises and the government can popularize the tea and other relevant knowledge, promote the health effects of tea, and encourage the simplification of tea packaging and other measures to achieve the goal of promoting the public tea. Specifically speaking: first, tea enterprises, industry associations and government departments coordinate with each other, establishing the promotion platform of tea culture and professional knowledge which aims at the public. They ought to jointly promote the education and popularization of tea culture knowledge to enhance the consumer's tea awareness level. Focus on the choice of public information and brand communication channels to enhance the public welfare, leisure and authority of publicity, to strengthen the business environment of information dissemination as far as possible. Second, create "light packaging, good quality" tea products. First-line production tea farmers and tea merchants should be conscious of paying attention to the production and processing of middle price tea in the future, and cannot blindly produce high prices and high quality tea. They need simplify the appearance of packaging, putting environmentally friendly, biodegradable and reusable tea packaging materials into the market, and get rid of "luxury" and "face project", so that the tea packaging is practical and creative, concise but not simple. Third, considering the different willingness of consumption of consumers in different age, take various market methods to meet the demand of consumers, to promote the public tea will to be converted into the actual purchase behavior.

\section{ACKNOWLEDGMENT}

Author: Ping Chen(1983-), female, Fuzhou, Fujian, doctoral student, college of economic, Fujian Agriculture and Forestry University. E-mail: 1041343189@qq.com.

Corresponding author: Jiangfan Yang, professor, Fujian Agriculture and Forestry University, research direction being for the tea industry economy and management.

Program of Foundation: China Oolong Tea Collaborative Innovation Project, 2011(Program Code: K8015H01C)

\section{REFERENCES}

[1] Chen Ping, Wang Yuting, Guan Xi, etc. Fujian residents tea consumption behavior survey [J]. Forestry economic problems, 2016, 36 (4): 369-372.

[2] Liu Jiajia, Li Daohe, Tan Zhaowei. Empirical Analysis on the Influencing Factors of Consumers' Purchase Intention of Tea - Based on Jiangxi Province Survey Data [J]. Rural Economy and Technology, 2015 (9): 98101.

[3] Zhan Huibin. The Exploration of the Influencing Factors of the Consumers' Willingness of Purchasing Geography Brand ProductsTake the Tea with Geography Brand of Mountain Huang [J]. Journal of Hebei University of Engineering (Social Science Edition), 2011, 28(1):18-20.

[4] Zhang Mei. Consumer tea oil purchase intention influencing factors empirical analysis - based on the survey of Guangzhou consumers [J]. Southern rural areas, 2014 (1): 4-7.

[5] Sandalidou E, Baourakis G, Siskos Y. Customers' perspectives on the quality of organic olive oil in Greece. A satisfaction evaluation approach.[J]. British Food Journal, 2002, 104(3/4/5):391-406.

[6] Huang Zuhui, Qian Fengyan, Li Huangzhao. The Analyze on the Feature of Tea Safety and Consumption [J]. Journal of Zhejiang University (Humanities and Social Sciences), 2004, 34 (3): 21-26. 